\title{
SUMMARY OF SCAN SITE 4
}

\author{
G. W. Moore, U. S. Geological Survey, La Jolla, California \\ and \\ G. F. Sharman, Scripps Institution of Oceanography, La Jolla, California
}

\section{OBJECTIVES OF DRILL HOLE}

Site 4 is located at latitude $40^{\circ} 40^{\prime} \mathrm{N}$, longitude $127^{\circ}$ $30^{\prime} \mathrm{W}$, in a water depth of 3240 meters. This site is in the Escanaba Trough, a central rift at the crest of Gorda Rise. The Escanaba Trough is near an abundant source of terrigenous sediment and contains approximately 500 meters of sediment, despite its presumed youth. This geographic accident makes the site especially promising for investigating all aspects of an active line of sea-floor spreading. Heat-flow studies and a search for volcanogenic mineral deposits of the Red Sea type will be of particular interest.

\section{SURVEY METHODS}

The preliminary survey of this site was made from the Argo between March 13-15, 1969. Navigation was by Loran A, with a fix precision of approximately 2 kilometers. Magnetic-intensity traverses and acousticreflection profiles at $12,3.5$ and $0.1 \mathrm{kHz}$ were run on a rectangular grid of 75 by 100 kilometers. The track spacing of the grid ranged from about 10 to 30 kilometers. On the accompanying subbottom profiles, a 10 -second sweep was used and the distance between hour marks is approximately 20 kilometers. A piston core was taken at latitude $40^{\circ} 44^{\prime} \mathrm{N}$, longitude $127^{\circ}$ $31^{\prime} \mathrm{W}$, and deep-sea photographs at $40^{\circ} 41^{\prime} \mathrm{N}, 127^{\circ} 31^{\prime} \mathrm{W}$.

\section{NATURE OF SITE}

A presumably volcanic ridge, about 45 meters high, was discovered by this survey at the center of Escanaba Trough; and, Site 4 lies to the west. The ridge is flanked by a narrow graben that cuts the surface sediment. The uppermost sample from the piston core contains Pleistocene rather than Holocene coccoliths, so sedimentation is probably much slower now than it was when the continental shelf was uncovered during the Pleistocene. Sediment near the surface is dark greenish-gray plastic to slightly fissile clay with some sandy layers.

\section{MICROPALEONTOLOGY}

\author{
David Bukry \\ U. S. Geological Survey, La Jolla
}

\section{General Comments}

Samples at 1.5-meter intervals from piston cores taken during the preliminary surveys of the proposed Deep Sea Drilling Project sites in the northeast Pacific have been examined for calcareous nannofossils. The identified assemblages of nannofossils indicate that Pliocene sediment containing abundant discoasters is present in the upper 10 meters at only one place, Site 6 . Elsewhere, only Pleistocene assemblages are present in the upper 10 meters. The abundant, widely distributed, Holocene nannofossil, Emiliania huxleyi (Lohmann) is not represented in any of the samples examined.

Diatoms are common only in surface samples ( 0 to 1 centimeter) at Sites 1,2 and 4 . Foraminifera are sparsely present in several samples from Sites 1, 2, 4, 5 and 6.

\section{SCAN-4-P}

Core length: 10.1 meters. Pleistocene calcareous nannofossils are present only in samples from the upper meter of the core. Only rarely occurring diatom fragments are present in the remainder of the core. 


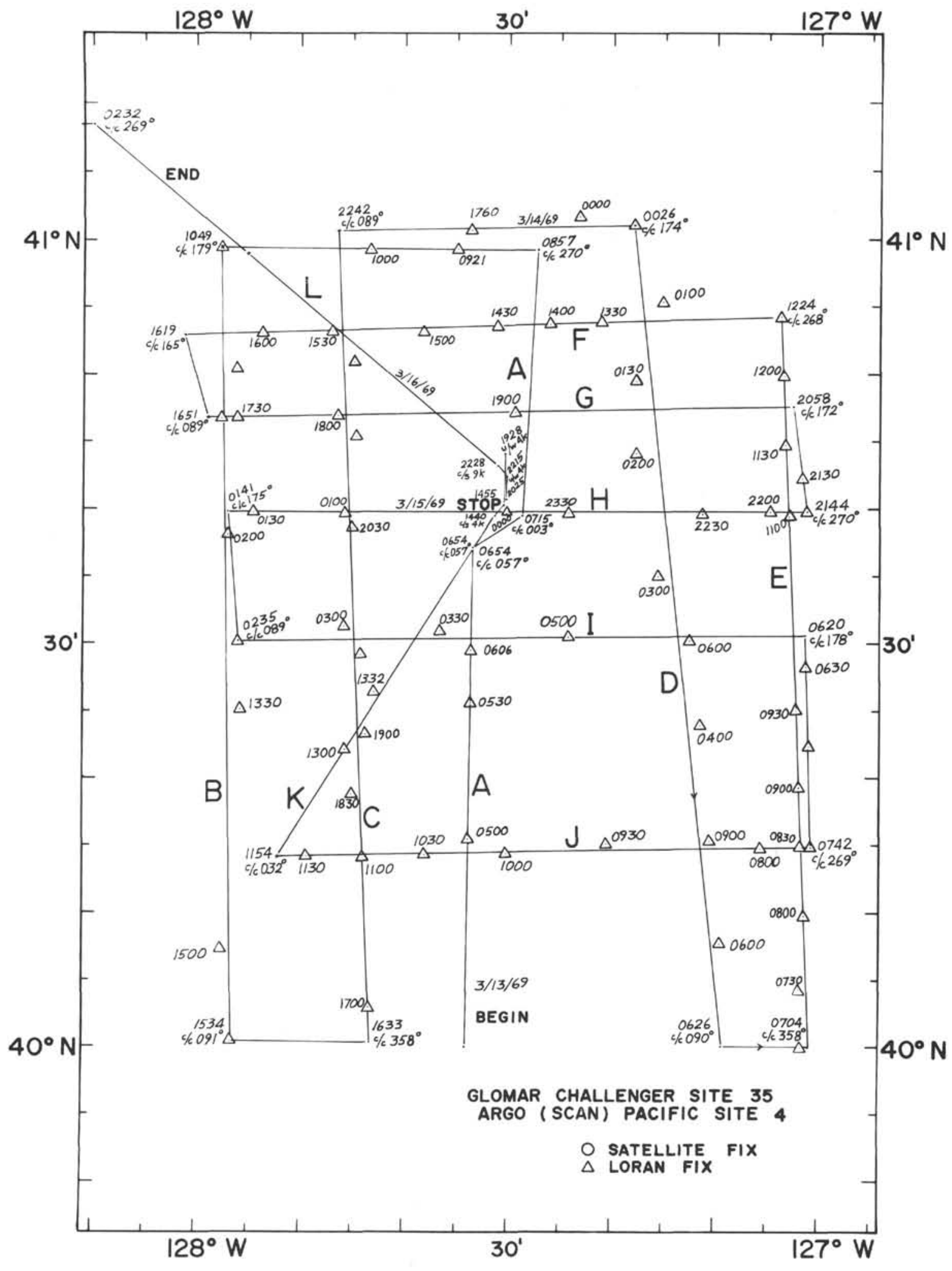



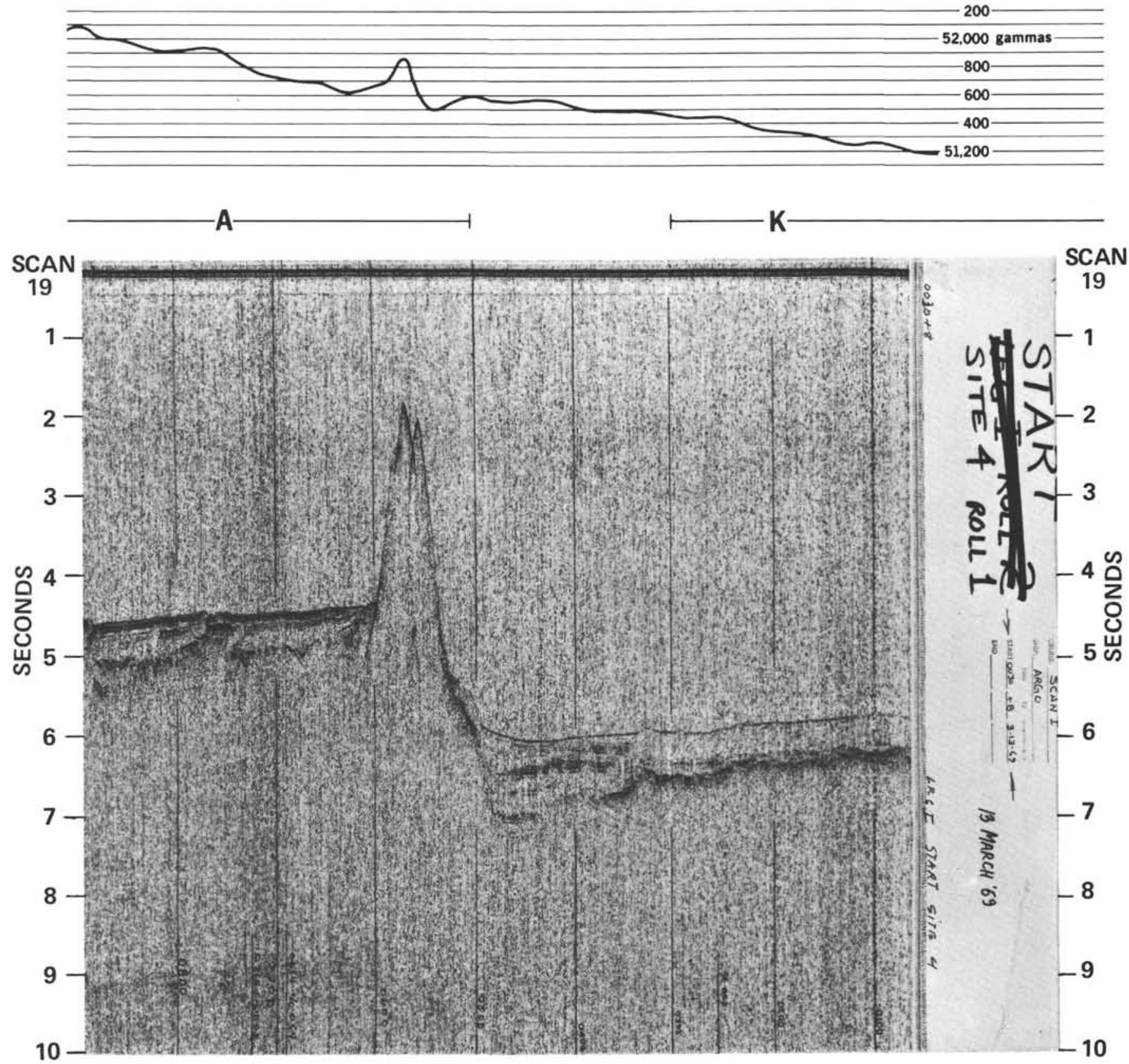

SCAN Survey, Sites 2 and 3, Track K; and, SCAN Survey, Site 4, Track A. 


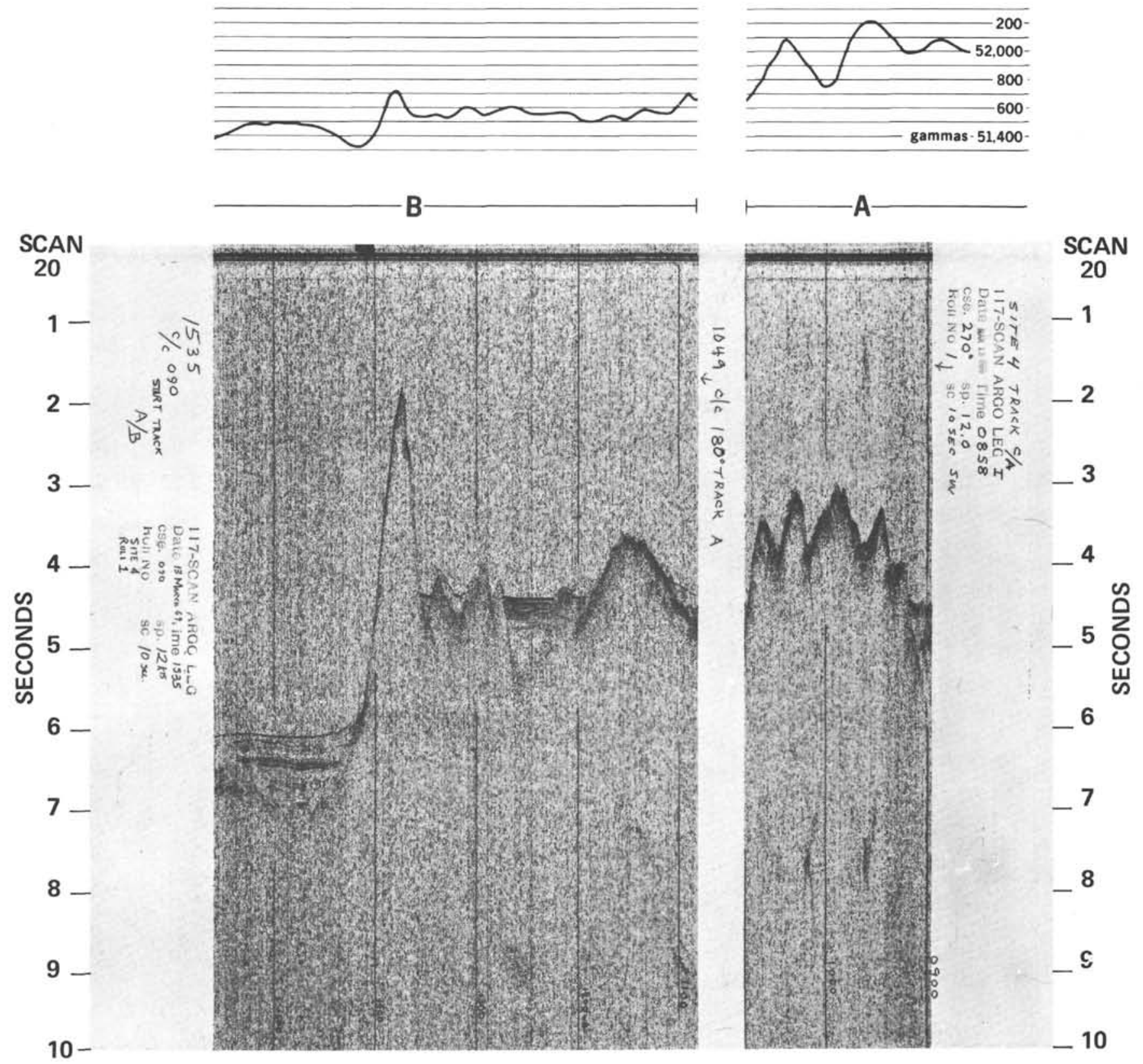

SCAN Survey, Site 4, Tracks $A$ and $B$. 


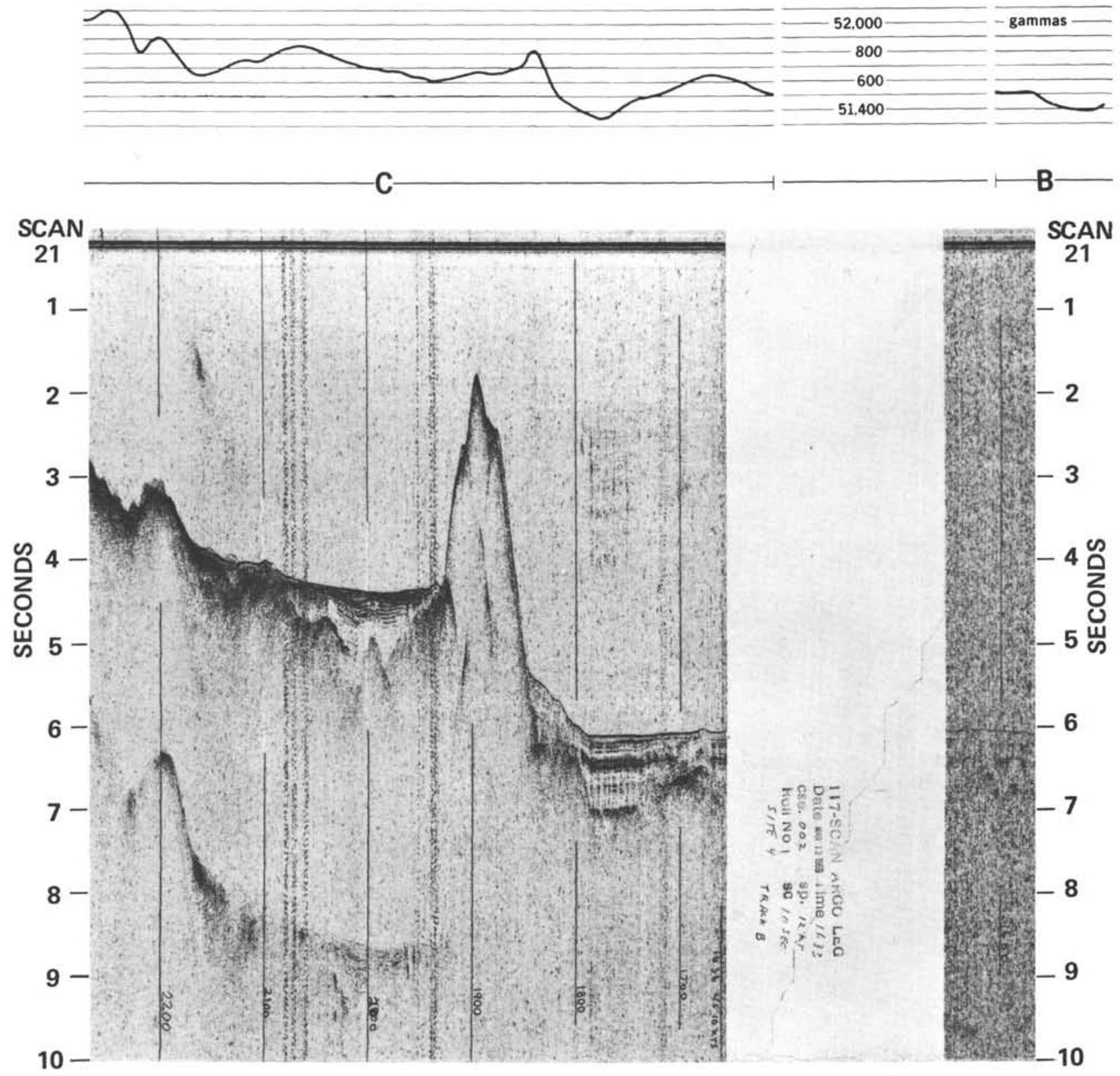

SCAN Survey, Site 4, Tracks B and C. 


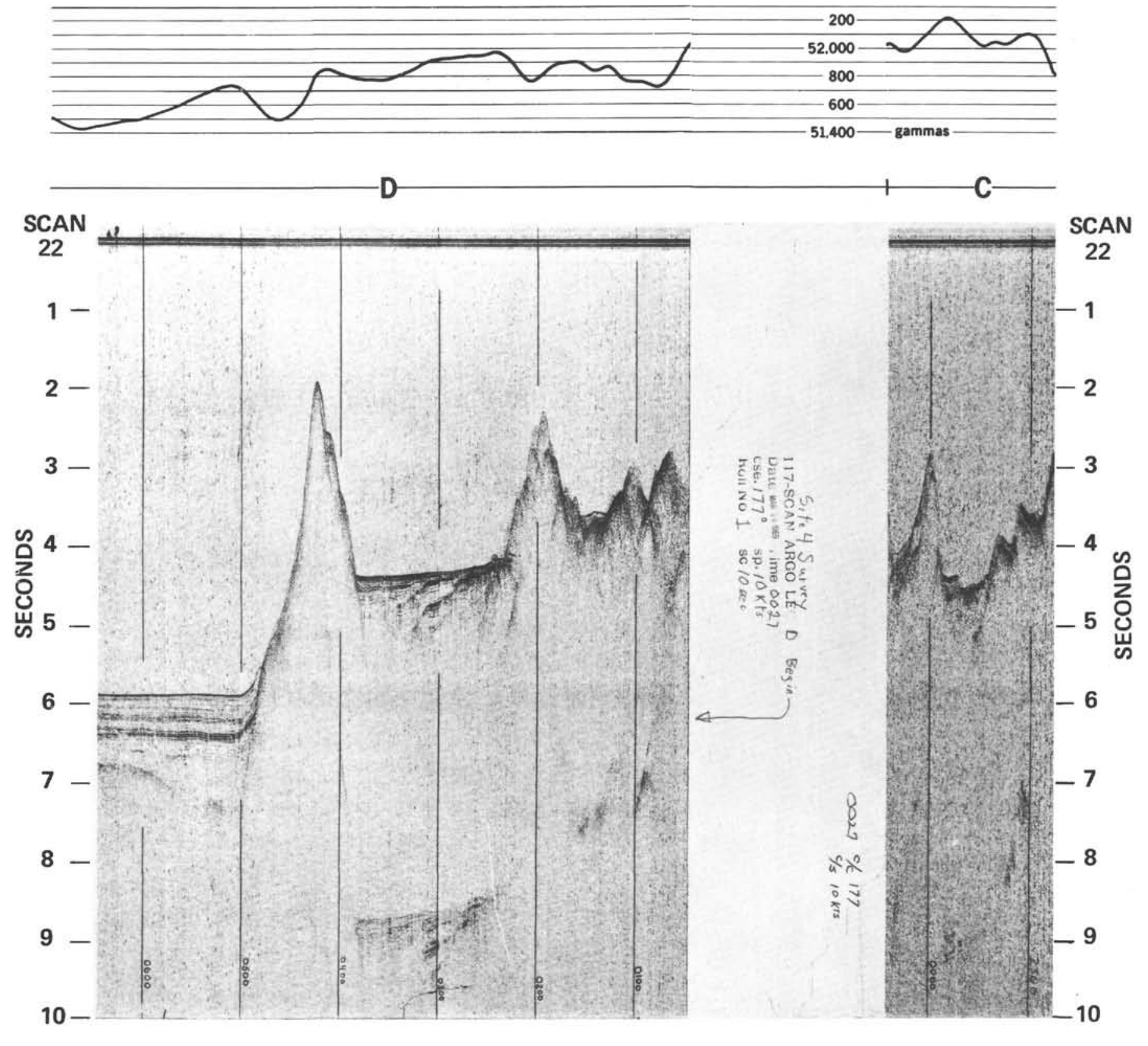

SCAN Survey, Site 4, Tracks $C$ and D. 

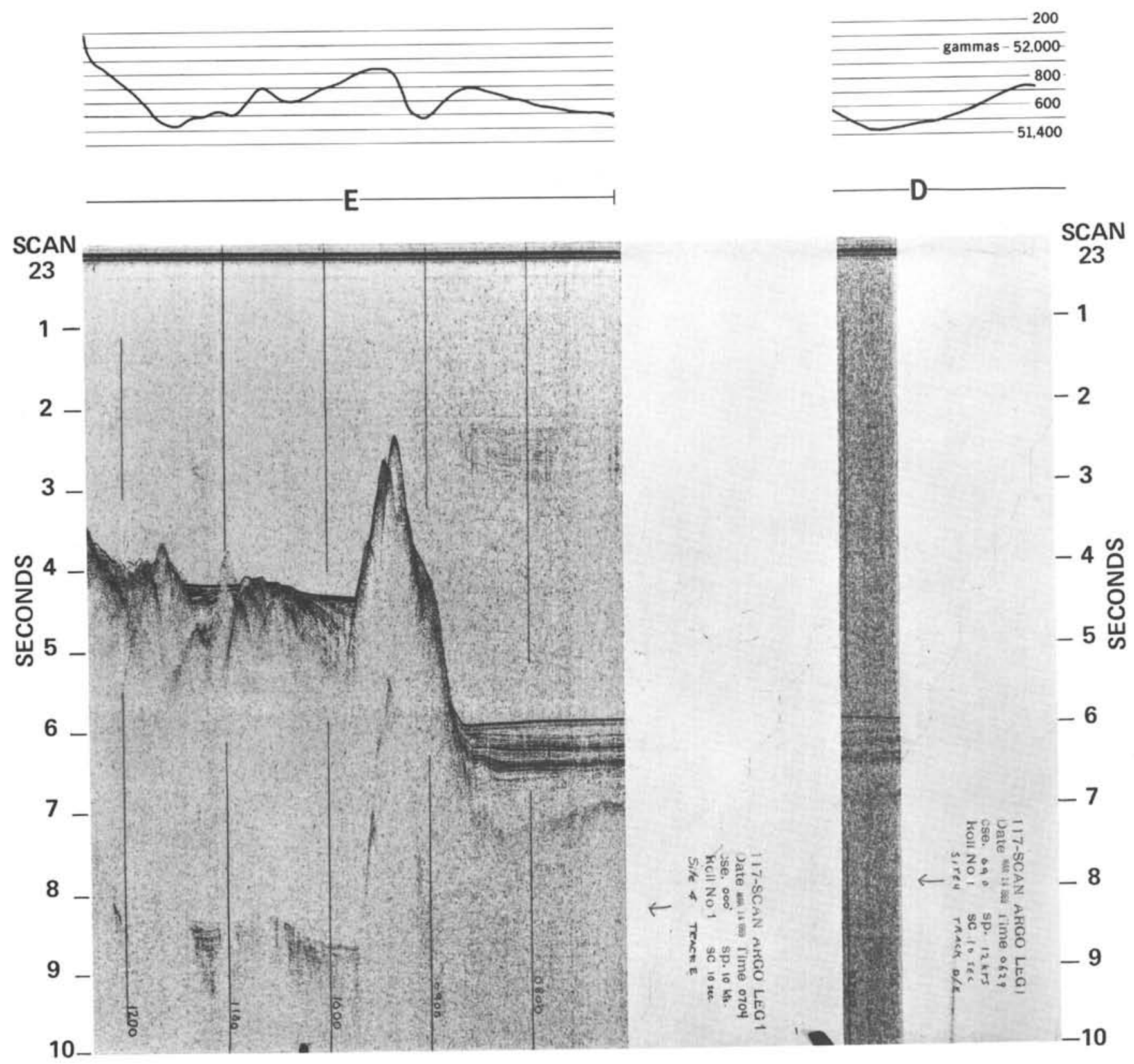

SCAN Survey, Site 4, Tracks D and E. 


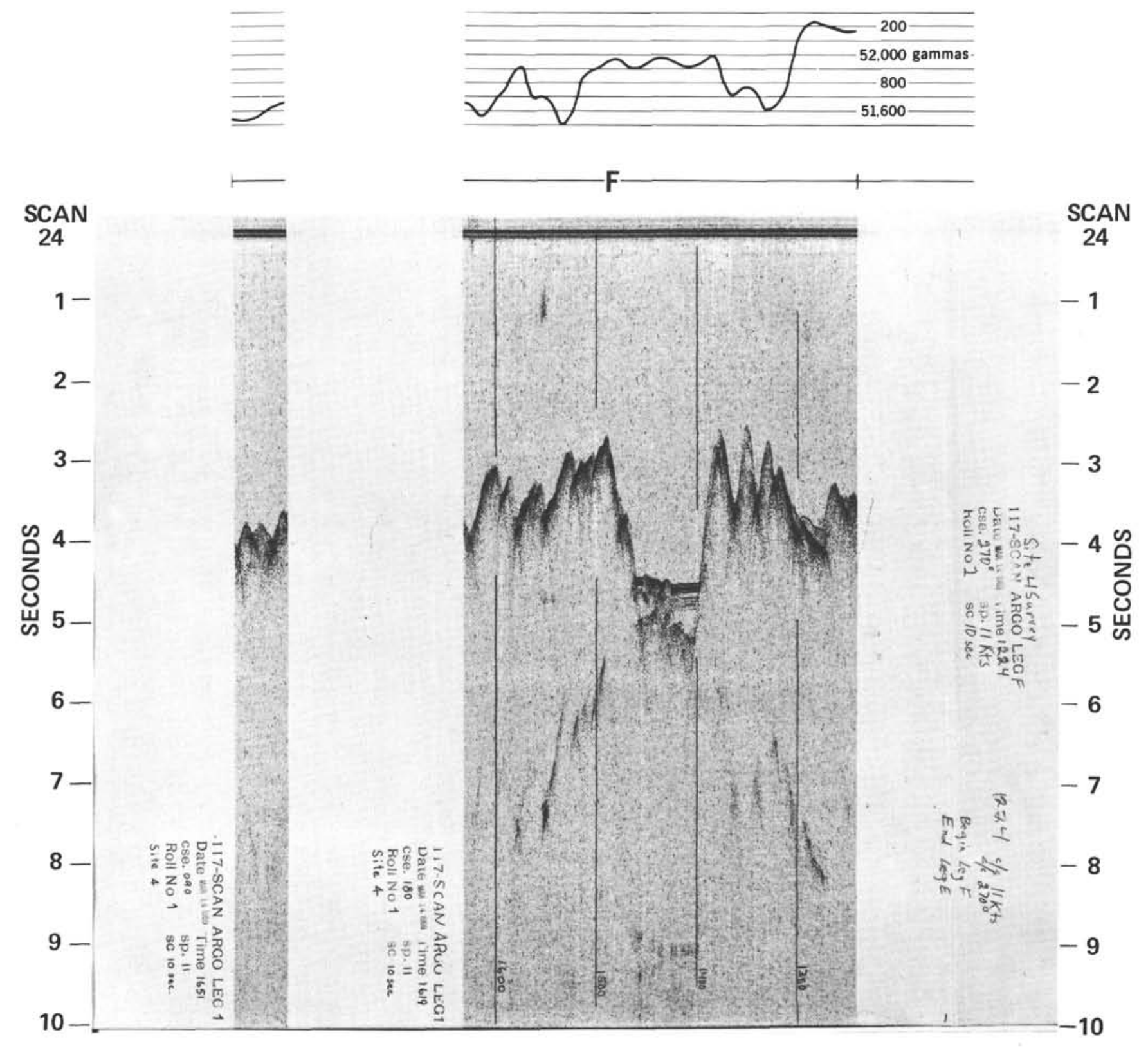

SCAN Survey, Site 4, Track F. 


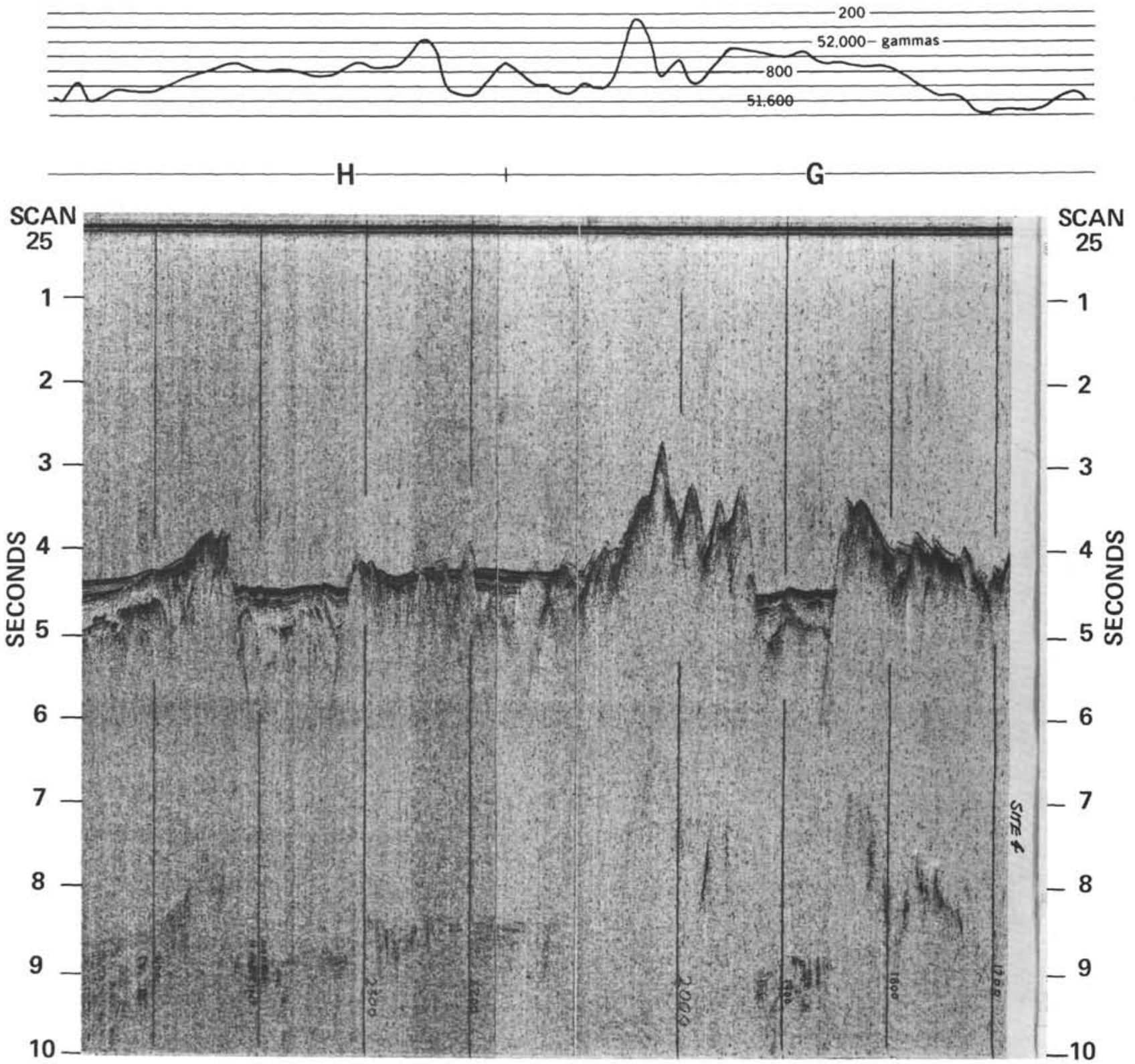

SCAN Survey, Site 4, Tracks $G$ and $H$. 

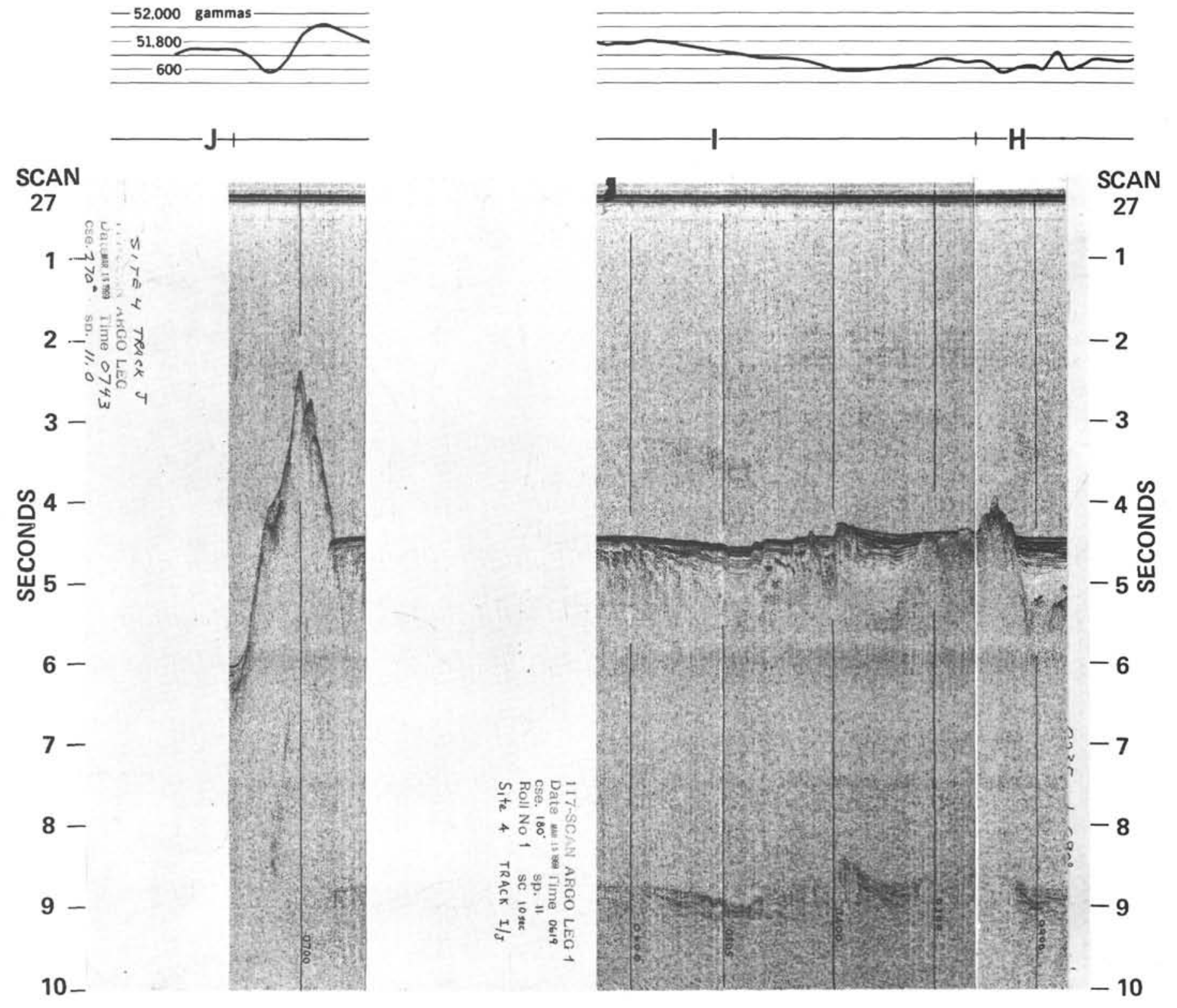

SCAN Survey, Site 4, Tracks H, I and J. 

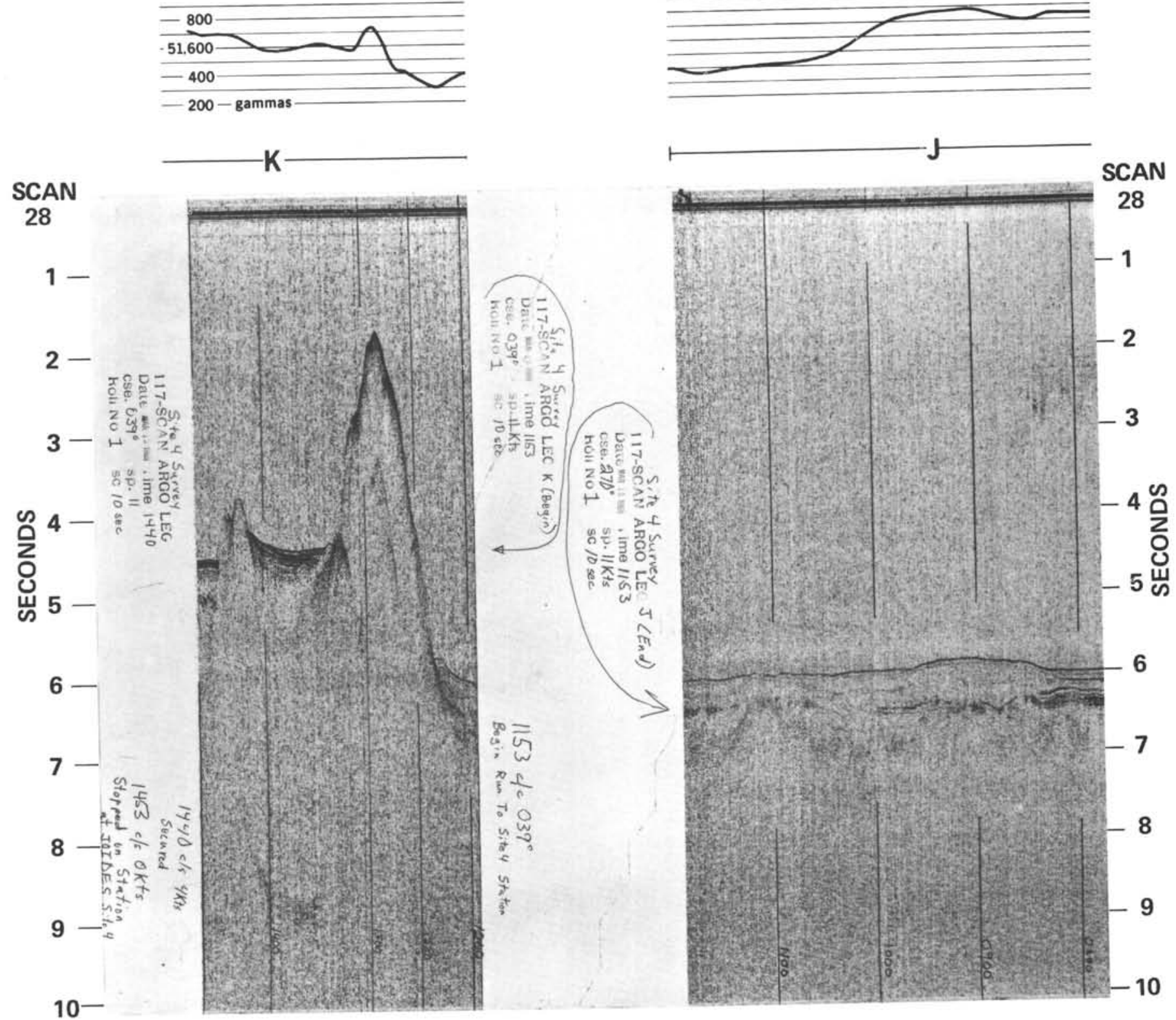

SCAN Survey, Site 4, Tracks $J$ and $K$. 

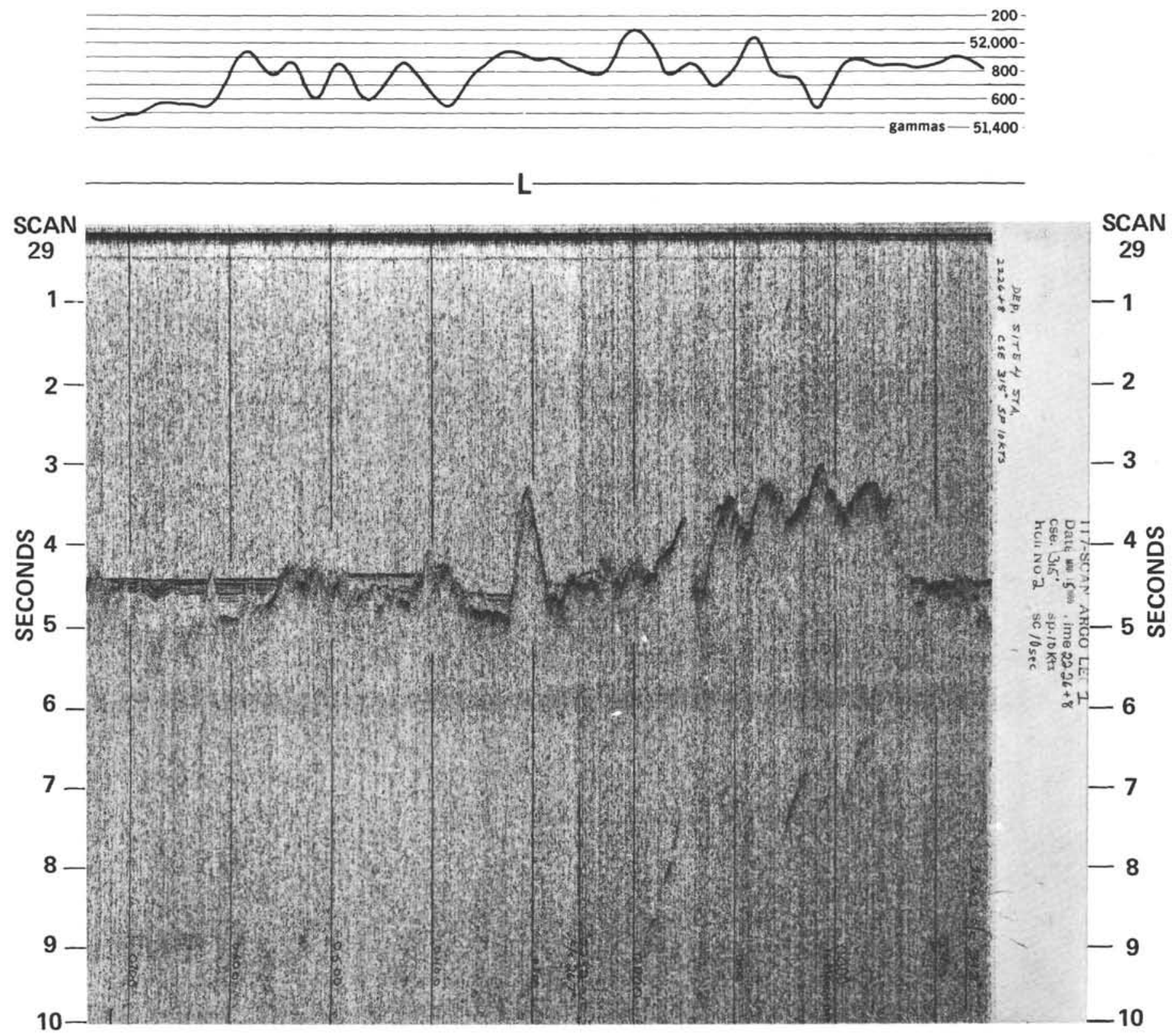

SCAN Survey, Site 4, Track L. 


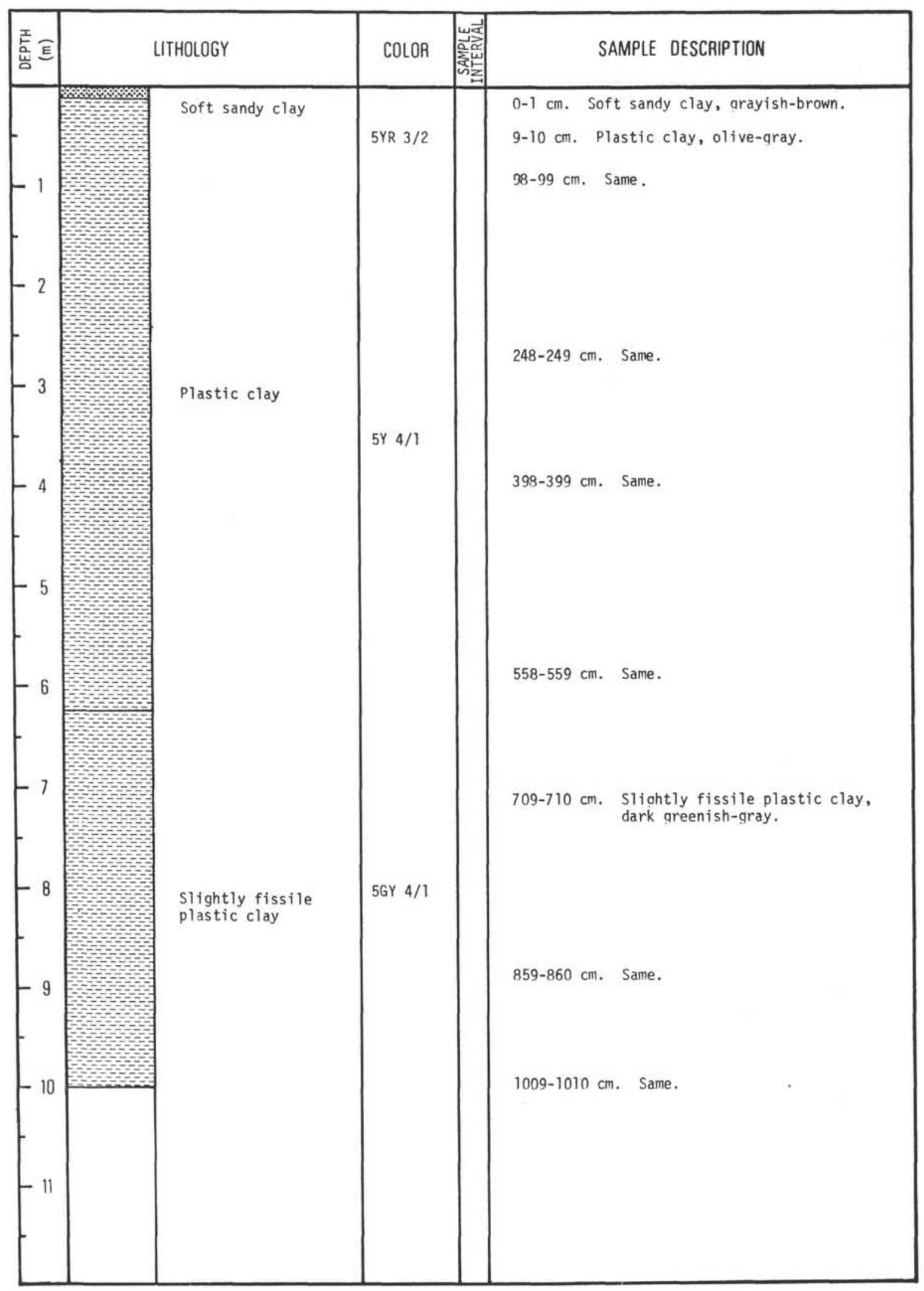

Summary of Piston Core 4. 